Berkala Ilmu Perpustakaan dan Informasi, Vol. 15, No. 2, Desember 2019, Hal. 149-162 DOI: 10.22146/bip.47370

ISSN 1693-7740 (Print), ISSN 2477-0361 (Online)

Tersedia online di https://jurnal.ugm.ac.id/bip

\title{
Mempertahankan keaslian arsip elektronik di era digital berdasarkan tinjauan literatur sistematis
}

\author{
Muhamad Idris Marbawi, Tamara Adriani Salim \\ Jurusan Ilmu Perpustakaan dan Informasi, Fakultas Ilmu Pengetahuan Budaya \\ Universitas Indonesia, 16424 Depok, Indonesia \\ e-mail:muhamad.idris81@ui.ac.id; tamaraas@ui.ac.id
}

Naskah diterima: 6 juli 2019, direvisi: 25 Oktober 2019, disetujui: 1 November 2019

\begin{abstract}
ABSTRAK
Pendahuluan. Penelitian ini bertujuan untuk mengetahui upaya-upaya apa saja yang harus dilakukan agar keaslian arsip elektronik itu dapat dipertahankan dalam era lingkungan digital.

Metode Penelitian. Penelitian ini menggunakan metode penelitian tinjauan sistematis terhadap literatur yang diterbitkan oleh jurnal ilmiah pada periode Januari tahun 2010 hingga April 2019 yang dilanggan oleh Perpustakaan Universitas Indonesia. Hasil tinjauan ini dilaporkan menggunakan pedoman Tinjauan Literatur Sistematis atau Systematic Literature Review (SLR) yang memiliki tiga tahapan, yaitu perencanaan, pelaksanaan, dan pelaporan.

Data Analisis. Penelitian ini menggunakan analisis deksriptif berdasarkan data yang ditemukan dengan menggunakan aplikasi statistik sederhana (Microsoft Office Excel 2007).

Hasil dan Pembahasan. Hasil yang diperoleh menunjukkan bahwa terdapat 18 literatur (hanya 3\%) dari total hasil pencarian sebanyak 561 literatur yang relevan membahas mengenai arisp elektronik dan cara yang diusulkan untuk mempertahankan keasliannya di era digital. Sejumlah 12 artikel yang memberikan informasi cukup mengenai hal tersebut.

Kesimpulan. Sebagaian besar dari artikel tersebut menyebutkan bahwa untuk mempertahankan keaslian arsip elektronik di era digital harus ada dukungan dari pembuat kebijakan untuk membuat pedoman mengenai batasan keaslian sebuah dokumen elektronik. Selain itu, masalah pengetahuan dan keterampilan para pengelola arsip, serta teknologi yang tepat guna juga diperlukan.
\end{abstract}

Kata Kunci: Keaslian arsip; kearsipan; rekod elektronik; era digital; pengelolaan arsip

\section{ABSTRACT}

Introduction. This research aimed to understand efforts should be taken so that the authenticity of electronic records can be maintained in the digital environment.

Data Collection Method. This research used a systematic literature review published by scientific journals from January 2010 to April 2019 derived from electronic information sources subscribed by the University of Indonesia Library. The results of this review are reported using guidelines for Systematic Literature Review (SLR) which has three stages, namely planning, implementation, and reporting.

Analysis Data. Descriptive quantitative was employed to analyze the data by using simple statistic application (Microsoft Office Excel 2007).

Results and Discussions. The results indicated that there are 18 literatures (3\%) of the total search results of 561 relevant literatures discussing electronic records and ways to maintain their authenticity in digital era. There were 12 articles providing sufficient information about this matter.

Conclusions. The majority of the articles mentioned that to maintain the authenticity of electronic archives in digital era must be supported by policy makers such as the government. In addition, the knowledge and skills of archival managers, as well as appropriate technology are also needed.

Keywords: Authenticity of archives; archives; electronic records; digital era; archive management 


\section{A. PENDAHULUAN}

Selama ribuan tahun, teori dan praktik kearsipan telah mendasarkan dirinya pada sebuah konsep fundamental bahwa lembaga arsip adalah tempat tepercaya untuk menjaga keandalan dan keaslian dari sebuah rekod/catatan. Konsep ini berasal dari hukum Romawi: Kode Justinian - serangkaian karya fundamental dalam yurisprudensi yang dikeluarkan antara tahun 529-534 M oleh Kaisar Justinian I - mendefinisikan arsip atau lembaga arsip sebagai "tempat publik di mana perbuatan/peristiwa disimpan agar tidak rusak, juga sebagai tempat yang menyediakan bukti yang dapat dipercaya dan menjadi ingatan berkelanjutan tentang apa yang mereka buktikan" (Duranti \& Jansen, 2013). Peran unik lembaga arsip ini dalam menjaga keaslian rekod/catatan yang dipindahkan dari lingkungan ciptaan aslinya untuk difungsikan sebagai bukti atau memori untuk generasi berikutnya dimungkinkan oleh serangkaian teori, metodologi, dan praktik kearsipan terintegrasi yang telah berkembang selama ribuan tahun. Tabularium Romawi - kantor catatan resmi Roma kuno - dirancang sedemikian rupa sehingga dokumen dapat dipindahkan secara aman dari kantor publik di Republik Roma menjadi tanggungan Tabularium Roma (Wei, Fang, Pan, \& Dekun, 2016). Dalam perjalanan sejarah keberadaan dokumen, hubungan antara tempat pelestarian dan pencipta dokumen telah berubah seiring waktu. Pada awalnya, tempat pelestarian (yaitu Tabularium Romawi) dan pencipta dokumen berada di bawah otoritas yang sama; kemudian, pada kekaisaran Roma, tempat pelestarian berada di bawah lembaga yang memiliki beberapa bentuk kedaulatan atas pencipta dokumen. Namun demikian, pelimpahan dokumen ke dalam lembaga arsip itu lebih dari sekedar deklarasi keasliannya; hal itu mengharuskan lembaga arsip menggunakan metodologi yang tepat untuk menjamin keaslian catatan dari waktu ke waktu. Hilary Jenkinson, salah satu arsiparis paling berpengaruh dalam dunia kearsipan berbahasa Inggris, menyatakan bahwa tugas utama pengarsipan adalah pertahanan fisik dan moral dari arsip yang dilestarikan (Wei, Fang, Pan, \& Dekun, 2016).

Mengenai "keaslian", istilah tersebut memiliki beragam definisi yang sangat bergantung kepada konteks penggunaannya. Zhu (2017) menyebutkan bahwa diskusi global tentang konsep keaslian memainkan peran penting dalam penelitian akademik tentang warisan budaya, konservasi, dan perencanaan restorasi, di samping prosedur prasasti Konvensi Warisan Dunia. Sementara itu Adam (2010) menyatakan bahwa dokumen historis yang otentik adalah dokumen yang membuktikan peristiwa yang sebenarnya terjadi atau pada informasi yang benar". Konsep keaslian arsip terkait erat dengan integritas objek. Jika sebuah objek arsip fisik digambarkan memiliki integritas, itu dipahami lengkap dan tidak berubah. Integritas berbicara tentang kedudukan objek dalam hubungannya dengan objek bentuk aslinya sedangkan keaslian berbicara apakah benda itu benar-benar seperti yang diklaim. Kedua konsep itu dalam banyak hal saling terkait dan diskusi apa pun tentang keaslian pasti akan mencakup pertanyaan tentang integritas (Adam, 2010). Sementera itu, model referensi untuk sistem informasi arsip terbuka (Reference Model for an Open Archival Information System) mendefinisikan keaslian sebagai sejauh mana orang (atau sistem) menganggap suatu objek seperti apa yang seharusnya. Jadi keaslian itu merupakan bentuk awal setelah selesai diciptakan dan memiliki tujuan tertentu (OAIS, 2012).

Seiring dengan perkembangan teknologi informasi dan komunikasi yang ditandai dengan kemunculan komputer dan teknologi pemindai yang mampu untuk memindai hampir semua dokumen untuk disebarkan dan dikirim secara elektronik, baik itu ke perorangan maupun kelompok, bentuk dan format dokumen juga mengalami perubahan, dari bentuk fisik ke bentuk elektronik. Hal ini mempengaruhi paradigma dan cara pandang kita terhadap keberadaan dokumen yang tersebar secara luas.

Cara kita menyimpan dan memperlakukan dokumen elektronik tentu berbeda dengan 
perlakuan kita terhadap dokumen fisik yang membutuhkan ruang fisik dan secara berangsurangsur mengakuisisi ruang tempat kita bekerja. Dokumen elektronik memang membutuhkan tempat penyimpanan, tapi secara virtual berada dalam ruang maya yang dioperasikan secara elektronik. Namun demikian, berbeda dari informasi yang dibuat, dan disajikan dalam bentuk fisik secara konvensional dan tradisional, catatan dalam bentuk elektronik itu harus diproses terlebih dahulu oleh peralatan elektronik, agar dapat dilihat oleh mata manusia.

Dalam perkembangan dunia digital, kita tidak melihat fisik dokumen, tetapi tampilan komponen rakitan digital dalam bentuk aliran bit yang disusun oleh set aturan yang berinteraksi di berbagai lapisan teknologi (sistem operasi, transportasi, protokol, aplikasi perangkat lunak, dll.) yang ditulis dalam bahasa yang tidak dapat dibaca atau dipahami oleh manusia secara langsung. Ini menyiratkan bahwa integritas fisiknya, seperti jumlah bit string-nya yang tepat, mungkin dikompromikan, asalkan artikulasi konten dan elemen formulir yang diperlukan tetap sama (Adam, 2010). Secara umum, Adam (2010) menemukan dalam penelitiannya bahwa keaslian sebuah dokumen, baik itu fisik maupun elektronik adalah tanggung jawab dari arsiparis yang bekerja pada lembaga arsip.

Dengan semakin berkembangnya teknologi penciptaan gambar digital atau digital imaging dan semakin banyaknya konten-konten yang tersebar melalui media sosial, sangat dimungkinkan terjadinya perubahan terhadap bentuk asli dan penyalahgunaan terhadap sebuah dokumen elektronik karena sifatnya yang dapat ditransfer secara elektronik, maka penyebarannya pun dapat berlangsung dengan sangat cepat melalui jaringan internet. Berdasarkan penelusuran yang dilakukan oleh penulis pada beberapa jurnal elektronik, masalah yang khusus terkait keaslian arsip atau dokumen elektronik dalam lingkup kearsipan masih belum menjadi fokus utama penelitian yang terumuskan dalam pertanyaan penelitian.

Mengenai pengiriman/transfer dokumen elektronik melalui jaringan internet, Pertiwi (2019) menuliskan dalam laman www.tekno.kompas.com bahwa pada settingan asal, semua dokumen yang dikirim melalui media sosial (seperti Whatsapp ${ }^{\circledR}$ ) akan diterima dalam keadaan blur atau terlihat samar karena kualitasnya diturunkan dari aslinya. Hal itu disebabkan karena Whatsapp ${ }^{\circledR}$ mengompresi file foto yang dikirim, sehingga ukurannya lebih kecil dan agar mudah ditransfer. Hal ini berarti, bahwa hampir semua dokumen yang dikirim melalui media sosial mengalami perubahan struktur bentuk dari aslinya atau dengan kata lain sudah tidak asli alias salinan. Hal ini tentu sangat menjadi penting ketika dalam dunia administrasi, karena dokumen asli lah yang diperhitungkan dan diakui, meskipun terdapat salinan yang hampir mirip dengan aslinya. Atas dasar inilah, penelitian ini dilakukan untuk dapat memahami nilai keaslian dari dokumen elektronik dan bagaimana menjaga keaslian dari dokumen yang terlahir secara elektronik tersebut, sehingga keberadaannya dapat mejadi dasar bagi pengambilan keputusan untuk kepentingan masa depan yang lebih baik dengan menggunakan metode tinjauan literatur sistematis.

Permasalahan dalam penelitian ini adalah bagaimana pengelola arsip sebagai pihak terpercaya melakukan usaha-usaha untuk mempertahankan keaslian dari rekod/catatan elektronik tersebut agar tetap seperti pertama kali diciptakan? Berdasarkan pertanyaan penelitian tersebut, maka penelitian ini bertujuan untuk mengetahui upaya-upaya apa saja yang harus dilakukan oleh pengelola arsip untuk mempertahankan keaslian rekod/catatan elektronik yang menjadi tanggungannya atau yang berada dalam pengawasannya agar keadaannya tetap seperti pertama kali diciptakan dan pada saat rekod itu dipindahkan ke pengelola arsip.

\section{B. TINJAUAN PUSTAKA}

Secara etimologi, kata "authenticity" atau keaslian adalah kelayakan untuk diterima atau diyakini sesuai atau berdasarkan fakta; dibuat atau dilakukan dengan cara yang sama dengan aslinya; tidak salah atau imitasi (merriamwebster, 2019). Pengertian tersebut, jika dihubungkan dengan konsep sebuah rekod atau 
catatan yang asli, akan mengandung pemahaman bahwa rekod atau catatan itu adalah asli bukan imitasi atau tiruan atau hasil dari penggandaan.

Istilah otentik atau keaslian memiliki beragam definisi yang sangat bergantung kepada konteks penggunaannya. Menurut Duranti seperti dikutip oleh Adam (2010) bahwa "secara diplomatis dokumen asli atau dokumen yang otentik adalah dokumen yang ditulis sesuai dengan praktik waktu dan tempat yang ditunjukkan dalam teks, dan ditandatangani dengan nama orang yang kompeten untuk menciptakan dokumen tersebut. Konsep keaslian atau keaslian arsip terkait erat dengan integritas objek. Sebuah objek arsip fisik digambarkan memiliki integritas, itu dipahami sebagai suatu yang lengkap dan tidak berubah, seperti sebuah dokumen dalam bentuk media kertas yang berisi mengenai data lahir seseorang. Integritas berbicara tentang kedudukan objek dalam hubungannya dengan bentuk aslinya pada saat pertama kali diciptakan, sedangkan keaslian berbicara mengenai apakah benda itu (dokumen) benarbenar seperti yang diklaim pada peruntukan awalnya. Jadi, integritas itu difahami sebagai sesuatu yang relatif (dalam arti bahwa dokumen itu dapat termanifestasi di atas media kertas maupun media elektronik). Kedua konsep itu dalam banyak hal saling terkait dan diskusi apa pun tentang keaslian pasti akan mencakup pertanyaan tentang integritas (Adam, 2010).

Keaslian benda fisik dapat (dan bisa dibilang harus) dinilai kembali dari waktu ke waktu atau mengikuti perubahan yang berarti atau relevan, tetapi sebagai objek tersebut relatif statis pada saat diterima, proses mengevaluasi keaslian adalah umumnya terbatas pada penilaian selama aksesi dan, akibatnya, dianggap sebagai sesuatu yang didirikan dan diperbaiki. Berlawanan dengan persepsi ini, sifat objek digital dan praktik standar yang terlibat dalam melestarikannya telah menyoroti perlunya tinjauan keaslian atau keaslian yang sedang berlangsung. Berbeda dengan hubungan tradisional arsiparis dengan objek fisik, cara dan tingkat di mana objek digital berada diciptakan, sifat dinamis mereka, dan manipulasi yang berkelanjutan diperlukan untuk pelestariannya telah menyebabkan arsiparis memainkan peran yang lebih aktif dan berkelanjutan dalam tekad dan pelestarian keaslian sebuah dokumen (Adam, 2010).

Sabharwal (2017) menguatkan pernyataan Rosenzweig yang menunjukkan bahwa "keaslian" dan "kepercayaan" yang biasanya terkait dengan sumber utama historis dalam format cetak (kecuali untuk yang dipalsukan dan bahan fabrikasi) menampilkan masalah serius dalam memvalidasi konten cetakan digital telah datang dengan fitur unik seperti tanda air dan keunikan di serat kertas, diferensiasi sistematis belum terjadi dengan konten digital. Bahkan di mana master digital (seperti: File TIFF atau PDF / A) mungkin asli, sulit untuk menetapkan keasliannya tanpa adanya dokumentasi internal yang dilindungi kata sandi. Metadata untuk teks sejarah harus berisi dokumentasi seperti sumber informasi serta tanda tangan digital, bersama dengan kemungkinan data yang dienkripsi lainnya yang akan disimpan ke dalam file PDF / A, untuk membantu peneliti menetapkan keaslian dan kredibilitas master digital dan pengganti digital yang dapat diakses publik. Keuntungan format file ini adalah dapat mencegah pengguna (selain kurator) untuk mengubah dokumentasi informasi yang tertanam dalam file.

\section{METODE PENELITIAN}

Tinjauan literatur sistematis ini didasarkan pada pedoman Tinjauan Literatur Sistematis atau Systematic Literature Review (SLR) untuk pembuatan software oleh Okoli \& Schabram, (2010). Tahapan yang terdapat dalam metode SLR tersebut disederhanakan oleh Adrian, Abdullah, Atan, \& Jusoh (2016) sehingga menjadi terdiri dari tiga tahapan yang mencakup perencanaan, pelaksanaan, dan pembuatan laporan seperti yang ditampilkan pada Gambar 1. Tahapan perencanaan melihat protokol yang strukturnya berdasarkan konteks penelitian tertentu, mendefinisikan protokol tinjauan dan menyusun pertanyaan penelitian. Kemudian dilanjtukan dengan melaksanakan tahap berikutnya yaitu melakukan pencarian dan ekstraksi data untuk mengategorisasi item-item 
data sebagai hasilnya. Tahapan terakhir yaitu tahap pelaporan yang menyimpulkan hasil penelitian dan diskusi yang diajukan.

\section{Pertanyaan Penelitian}

Pada tahapan perencanaan ini, kriteria pertanyaan untuk penelitian ini disusun berdasarkan PICOC (Population, Intervention, Comparison, Outcomes and Context) yang pertama kali dibicarakan pada tahun 2006 oleh Petticrew \& Roberts. Dasar kriteria tersebut kemudian dibahas dan digunakan oleh para peneliti di berbagai disiplin, di antara penelitian yang telah membahas dan menggunakannya adalah Uman (2011), Garcia, Davila, \& Pessoa (2014), Shaikh, Salleh, \& Marziana (2015) dan Adrian, Abdullah, Atan, \& Jusoh (2016). Cakupan untuk penyusunan pertanyaan tinjauan ini ditunjukkan pada Tabel 1.

Berdasarkan kriteria dan cakupan tersebut pada Tabel 1, ada dua pertanyaan penelitian (PP) yang disusun, yaitu:PP1:Berapa banyak penelitian mengenai upaya-upaya untuk mempertahankan keaslian arsip elektronik yang sudah dilakukanPP2:Upaya-upaya apa saja yang harus dilakukan untuk mempertahankan keaslian arsip elektronik di era digital

\section{Strategi Pencarian}

Pada tahapan pelaksanaan, strategi pencarian dilakukan untuk memasukkan perumusan istilah pencarian, mencari sumber data dari database online, merumuskan kriteria inklusi dan eksklusi, dan penilaian kualitas penelitian.

a. Istilah Pencarian

Dalam melakukan pencarian mengenai penelitian ini, istilah pencarian yang digunakan adalah istilah yang berasal dari bahasa Inggris dan merupakan gabungan kata-kata kunci dengan menggunakan operator Boolean AND sebagai berikut:

Maintaining AND authenticity AND archives AND "digital age"

b. Sumber-sumber Literatur

Sumber-sumber literatur yang digunakan dalam tinjauan ini dengan menggunakan fasilitas pencarian Summon Discovery Search berdasarkan pada electronic resources (e-resources) yang dilanggan oleh perpustakaan Universitas Indonesia yang terdiri dari sekitar 29 database, yaitu: Annual Reviews, Cambridge Core, EBSCO Host, JSTOR, Oxford Academic, ProQuest, SAGE Journals, ScienceDirect, SpringerLink, Emerald Insight, Taylor \& Francis Online, Clinical Key, DynaMed, Medline, IBM Micromedex, Wiley Online Library, ACM, ACS, AIP, APS, ASCE, ASME, IEEE Explore, IOPScience, Royal Society of Chemistry, PsycArticles, Kluwer, HukumOnline.com, dan Westlaw. Beberapa artikel dikutip menggunakan teknik pencarian bola salju (snowballing technique search) melalui database elektronik. Sumber-sumber yang relevan kemudian disimpan dalam alat manajemen referensi untuk dilakukan pemilihan. Literatur yang dikutip dalam tinjauan ini dengan mempertimbangkan publikasi yang hanya diterbitkan pada periode Januari tahun 2010 hingga akhir bulan April tahun 2019.

c. Kriteria Inklusi dan Eksklusi

Kriteria inklusi (penyertaan) dan eksklusi (pengecualian) digunakan untuk mengeluarkan artikel-artikel yang tidak relevan dengan jawaban pertanyaan penelitian. Kedua kriteri inklusi dan eksklusi tersebut ditampilkan pada Tabel 2.

d. Penilaian Kualitas Penelitian

Penilaian kualitas dirumuskan untuk mengevaluasi kelengkapan dari artikel jurnal yang disaring menggunakan kriteria inklusi dan eksklusi serta menguntungkan untuk ekstraksi data. Pertanyaanpertanyaan ini disajikan pada tabel 3. Setiap pertanyaan hanya memiliki 3 jawaban alternative, yaitu: $Y a=2$; Sebagian $=1$; dan Tidak $=0$.

\section{HASIL DAN PEMBAHASAN}

Berdasarkan hasil tahapan metode tinjauan literatur sistematis (SLR) pada Gambar. 1, pemilihan penelitian dibagi menjadi 3 tahapan seleksi. Pertama, pencarian digital dilakukan dan seleksi proses didasarkan pada judul, yang menghasilkan total 561 (lima ratus enam puluh 
satu) referensi yang dianggap relevan dengan topik ini. Pada tahap selanjutnya, bagian abstrak dan konten singkat dari artikel yang dipilih lalu dievaluasi. Pada tahapan ini, ditemukan ada 4 (empat) artikel yang termasuk duplikat dan 468 (empat ratus enam puluh delapan) yang tidak relevan dengan kriteria inklusi dikeluarkan, sehingga menyisakan 84 (Delapan puluh empat) artikel yang relevan untuk dilakukan penliaian kualitas. Dari 84 artikel yang relevan tersebut kemudian disaring lagi dengan menerapkan kriteria PICOC yang mengeluarkan 66 (enam puluh enam) artikel yang tidak sesuai, sehingga menyisakan 18 (delapan belas) artikel terpilih. Akhirnya, 18 artikel terpilih tersebut (21 persen dari 84 artikel atau hanya 3 persen dari total 561 artikel yang ditemukan melalui pencarian database online) yang diterima untuk dilakukan sintesis data setelah melakukan penyaringan berdasarkan kriteria eksklusi dan skrining terperinci terhadap abstrak dan teks lengkap.

Hasil penyaringan dari penilaian kualitas artikel yang sudah terpilih dan sudah melewati tahapan pemilihan literatur diperlihatkan pada gambar 2. Penilaian tersebut menunjukkan bahwa ada 12 artikel (A1, A3, A5, A7, A9, A10, A12, A13, A14, A15, A 17, A 18) yang mendapatkan nilai 8; ada 1 artikel dengan kode artikel A16 yang memperoleh nilai 7; ada 2 artikel (A6 dan A8) yang mendapatkan nilai 5; dan ada 3 artikel (A11, A4, dan A2) yang masing-masing secara urut memperoleh nilai 4 , 3 dan 2. Sementara untuk rincian keterangan bibliografinya ada pada Tabel 4 .

Setelah melakukan penelusuran dan pencarian sumber-sumber informasi berupa artikel dari beberapa jurnal ilmiah, berikut hasil yang diperoleh berkaitan dengan pertanyaan penelitian ini yang sudah disampaikan pada bagian sebelumnya. Berikut jawaban dari dua pertanyaan tersebut:

1. Berapa banyak penelitian mengenai upaya-upaya untuk mempertahankan keaslian arsip elektronik yang sudah dilakukan (PP1)?

Berdasarkan penelusuran yang sudah dilakukan dengan menggunakan metode Tinjauan Literatur Sistematis (SLR), dihasilkan total 561 (lima ratus enam puluh satu) referensi yang dianggap relevan dengan topik ini. Pada tahap selanjutnya, bagian abstrak dan konten singkat dari artikel yang dipilih lalu dievaluasi. Pada tahapan ini, ditemukan ada 4 (empat) artikel yang termasuk duplikat dan 468 (empat ratus enam puluh delapan) yang tidak relevan dengan kriteria inklusi dikeluarkan, sehingga menyisakan 84 (Delapan puluh empat) artikel yang relevan untuk dilakukan penilaian kualitas. Dari 84 artikel yang relevan tersebut kemudian disaring lagi dengan menerapkan kriteria PICOC yang mengeluarkan 66 (enam puluh enam) artikel yang tidak sesuai, sehingga menyisakan 18 (delapan belas) artikel terpilih. Akhirnya, 18 artikel terpilih tersebut ( 21 persen dari 84 artikel atau hanya 3 persen dari total 561 artikel yang ditemukan melalui pencarian database online) yang diterima untuk dilakukan sintesis data setelah melakukan penyaringan berdasarkan kriteria eksklusi dan skrining terperinci terhadap abstrak dan teks lengkap.

Ditemukan bahwa ke-delapan belas artikel yang terpilih itu, semuanya menggunakan metode kuantitatif sebagai metode yang digunakan dalam melakukan penelitiannya, meskipun ada satu artikel yang menyatakan bahwa penulisnya menggunakan metode campuran atau mixed-method, yaitu pada artikel dengan kode A17 dengan judul "Exploring digital preservation requirements: A case study from the National Geoscience Data Centre (NGDC)" ditulis oleh Jaana Pinnick yang diterbitkan pada tahun 2017 oleh Records Management Journal di dalam database ProQuest. Sedangkan untuk skor penilaian kualitasnya, artikel A17 mendapatkan skor 8. Untuk melihat rincian nama-nama jurnal dan jumlah artikelnya yang terpilih dalam tinjauan ini dapat dilihat pada Tabel 4.

Sementara itu, jika dilihat dari tahun terbitan kedelapan belas artikel terpilih tersebut, artikel-artikel yang membahas mengenai arsip elektronik (termasuk rekod dan atau dokumen elektronik) selama 
periode awal 2010 hingga awal 2019 ratarata 2 artikel yang diterbitkan setiap tahunnya. Hanya pada tahun 2018 tidak ditemukan artikel yang menyinggung mengenai masalah tersebut. Ditemukan bahwa hanya pada tahun 2010 dan 2017 terdapat masing-masing 3 artikel yang terbit pada kedua tahun tersebut. Rinciannya dapat dilihat pada tabel 4.

2. Upaya-upaya apa saja yang harus dilakukan untuk mempertahankan keaslian arsip elektronik di era digital (PP2)

Untuk lebih memfokuskan pada jawaban untuk pertanyaan penelitian ini, peneliti membatasi hanya akan melakukan sintesis hail penelitian dari artikel-artikel yang memperoleh skor 8 dari delapan belas artikel terpilih, yaitu artikel-artikel dengan kode (A1, A3, A5, A7, A9, A10, A12, A13, A14, A15, A17, A18) yang rincian bibliografisnya ada pada tabel 4 . Berikut rangkuman mengenai upaya-upaya, baik yang sudah dilakukan atau berupa usulan yang harus dilakukan untuk mempertahankan keaslian arsip elektronik di era digital.

Artikel pertama dengan kode artikel A1 menunjukkan bahwa pengelola arsip atau arsiparis harus memperhatikan pemilihan cara yang tepat (baik dan benar) dalam usaha untuk mempertahankan bentuk asli dari arsip elektronik untuk memastikan pelestarian jangka panjang. Untuk itu, maka seorang arsiparis atau pengelola arsip elektronik/digital harus melakukan: 1) Menetapkan dari mana sebuah objek berasal dan apa yang dimaksudkannya; 2) Menentukan kualitas objek, konteks, dan kontennya dijaga agar tetap otentik dan, dengan demikian, menetapkan kriteria untuk keasliannya; dan 3) Menggunakan alat untuk memverifikasi bahwa objek tersebut adalah asli, serta salinan yang dibuat untuk pelestarian dan / atau distribusinya, terus memenuhi kriteria dari waktu ke waktu (Adam, 2010).

Artikel kedua dengan kode artikel A3 menyatakan bahwa profesional kearsipan atau arsiparis harus dilengkapi dengan pengetahuan dan keterampilan yang diperlukan untuk memenuhi mereka tanggung jawab mereka dalam mengelola arsip elektronik, yang harus diperoleh melalui pendidikan formal, dan membangun sistem pelestarian terpercaya yang mampu memastikan salinan asli yang akurat dari rekod penciptanya itu diperoleh dan dipertahankan (Mosweu \& Ngoepe, 2019).

Artikel ketiga dengan kode artikel A5 menyatakan bahwa untuk mempertahankan keaslian dokumen atau arsip elektronik diperlukan adanya standar internasional seperti ISO 15489 (International Standard on Records Management), ISO 16175 Persyaratan dasar dan fungsi untuk rekod dalam lingkungan elektronik, dan yang terbaru ISO 30300 tentang Sistem Manajemen untuk seri Rekod (Management System for Records series) (Evans, Reed, \& Linger, 2014).

Artikel keempat dengan kode artikel A7 menunjukkan bahwa untuk menjamin keaslian dan keandalan rekod/catatan, diperlukan kerangka kerja kebijakan, prosedur, teknologi, dan tindakan yang disengaja atau intervensi oleh entitas tepercaya - yuridis orang dijiwai dengan pertanggungjawaban terhadap catatancatatan itu. Konsep "pihak ketiga tepercaya pemegang catatan" dikembangkan dalam konteks kontrak elektronik dan mengacu pada orang fisik atau yuridis yang dipercayakan untuk melakukan pemeliharaan catatan (Duranti L., 2011).

Artikel kelima dengan kode artikel A9 menyatakan bahwa bahwa penggunaan teknologi komputerisasi diperlukan dalam upaya untuk mempertahankan keaslian arsip elektronik di era digital (Sabharwal, 2017). Artikel keenam dengan kode artikel A10 menyatakan bahwa kebijakan mengenai usaha untuk mempertahankan keaslian dokumen elektronik ada dan harus dikembangkan dengan pandangan ke arah bagaimana kebijakan itu dapat 
diinformasikan dan digunakan untuk memberi tahu berbagai pemangku kepentingan seperti donor, pembuat catatan, staf TI, dan peneliti. Praktik digunakan untuk mengelola dan melestarikan materi lahir-digital harus dipadatkan cukup untuk menjelaskan komitmen dan tanggung jawab lembaga sementara tetap cukup fleksibel untuk mengakomodasi inovasi dan pertumbuhan di masa depan. Hasil akhirnya mungkin bukan keamanan tanpa ketidakjelasan, tetapi kita akan memilikinya pemahaman yang lebih baik tentang cara mengidentifikasi, mengelola, dan mengandung risiko (jika tidak sepenuhnya melindungi) catatan arsip yang lahir secara digital (Goldman \& Pyatt, 2013).

Artikel ketujuh dengan kode artikel A12 menyatakan bahwa agar terjaganya keaslian dari dokumen elektronik itu, harus adanya pemeliharaan rutin agar keaslian arsip elektronik tetap terjaga, yaitu dengan cara: 1) Tetapkan pengidentifikasi di 'titik masalah' untuk aliran konten digital; 2) Pastikan bahwa konten digital diarsipkan secara rutin; 3) Beritahukanlah apa yang Anda kerjakan saat ini dan apa yang Anda simpan; dan 4) Publikasikan ketentuan akses untuk konten yang diarsipkan (sekarang dan ketika dianggap sebagai karya tak bertuan). (Burnhill, 2013). Artikel kedelapan dengan kode artikel A13 menunjukkan bahwa dalam mengelola koleksi khusus (termasuk arsip elektronik) diperlukan pemahaman yang baik tentang pemrosesan arsip dan aplikasi basis data; keahlian dan minat dalam bidang koleksi; pemahaman tentang kekayaan intelektual dan hak cipta; penjangkauan dan advokasi; dan kebanyakan dari semua adalah dukungan dari programmer yang berdedikasi (Evans M. R., 2015).

Artikel kesembilan dengan kode A14 menyinggung bahwa untuk menjaga keaslian dokumen elektronik itu diperlukan kebijakan untuk membangun repositori digital yang benar-benar dipercaya oleh pembuat informasi dan komunitas pengguna, suatu organisasi harus menunjukkan komitmennya terhadap sistem pelestarian digital yang memadai untuk memenuhi kebutuhan pelestarian digital dari waktu ke waktu. Ini termasuk kemampuan untuk melestarikan objek digital dengan keaslian dan integritasnya utuh, dan dengan memadai perlindungan terhadap degradasi media, bencana alam, dan kesalahan manusia. Juga termasuk kemampuan untuk me-render objek-objek itu, baik dalam format asli atau format baru yang menjaga integritas dan keaslian dokumen asli. Repositori digital yang terpercaya akan mempertahankan metadata yang cukup tentang objek menunjukkan integritas dan keaslian dokumen asli, serta mendokumentasikan semuanya migrasi media dan format, belum lagi pelestarian digital lainnya atau langkah-langkah aksesibilitas yang dilakukan oleh repositori (Price \& Smith, 2011).

Artikel kesepuluh dengan kode artikel A15 menunjukkan bahwa penggunaan teknologi komputerisasi dan sistem informasi diperlukan dalam upaya untuk mempertahankan keaslian arsip elektronik di era digital (Cohen, 2015). Artikel kesebelas dengan kode artikel A17 menyimpulkan bahwa teknologi dan organisai kearsipan atau yang melakukan pengelolaan arsip sangat berperan untuk mempertahankan keaslian arsip elektronik di era digital (Wei, Fang, Pan, \& Dekun, 2016). Artikel kedua belas dengan kode artikel A18 menyatakan bahwa untuk memastikan kesinambungan dokumen digital, penciptaan metadata berkualitas tinggi sangat penting, dan deposan data memerlukan manajemen data pelatihan untuk mencapai ini. Rekomendasi termasuk menyelesaikan penilaian risiko, menciptakan daftar aset digital dan pengawas teknologi untuk mengurangi risiko sehingga keaslian arsip elektronik dapat terjaga (Pinnick, 2017). 


\section{E. KESIMPULAN}

Sebagian besar dari artikel yang membahas tentang arsip elektronik (termasuk rekod dan dokumen elektronik) menyebutkan bahwa untuk menjaga atau mempertahankan keaslian arsip elektronik di era digital harus adanya dukungan dari pembuat kebijakan dalam hal ini pemerintah untuk membuat pedoman mengenai batasan keaslian sebuah dokumen elektronik. Selain itu, masalah pengetahuan dan keterampilan para pengelola arsip, serta teknologi (termasuk sistem) yang tepat guna juga diperlukan. Kebijakan diperlukan ntuk membangun repositori digital yang benar-benar dipercaya oleh pembuat informasi dan komunitas pengguna, suatu organisasi harus menunjukkan komitmennya terhadap sistem pelestarian digital yang memadai untuk memenuhi kebutuhan pelestarian digital dari waktu ke waktu. Ini termasuk kemampuan untuk melestarikan objek digital dengan keaslian dan integritasnya utuh, dan dengan memadai perlindungan terhadap degradasi media, bencana alam, dan kesalahan manusia. Juga termasuk kemampuan untuk me-render objek-objek itu, baik dalam format asli atau format baru yang menjaga integritas dan keaslian dokumen asli.

Dengan demikian maka sudah sepatutnya bagi pemangku kebijakan (dalam hal ini pemerintah yang menangani dokumentasi dan kearsipan) untuk membuat kebijakan yang menjadi dasar dan legalitas bagi terciptanya sebuah sistem yang dikembangkan berdasarkan perkembangan teknologi informasi dan komunikasi dalam rangka menjaga dan melestarikan keaslian dari dokumen dan arsip yang terlahir secara elektronik dengan berbagai bentuknya sehingga nilai dan fungsinya tetap terjaga sepanjang masa dan dapat dipergunakan kembali serta dimanfaatkan oleh generasi selanjutnya.

\section{DAFTAR PUSTAKA}

Adam, S. (2010). Preserving authenticity in the digital age. Library Hi Tech, 28(4), 595604.

Adrian, C., Abdullah, R., Atan, R., \& Jusoh, Y. Y. (2016). Towards developing strategic assessment model for big data implementation: A systematic literature review. International journal of advances in soft computing and its applications, 8(3), 173-192.

Bunakov, V., Jones, C., Matthews, B., \& Wilson, M. (2014). Data authenticity and data value in policy-driven digital collections. OCLC Systems \& Services: International digital libraryperspectives, 30(4), 212-231.

Burnhill, P. (2013). Tales from the keepers registry: Serial issues about archiving $\&$ the web. Serials Review, 39(1), 3-20.

Cohen, F. B. (2015). Digital diplomatics and forensics: Going forward on a global basis. Records Management Journal, 25(1), 2144.

Duranti, L. (2011). Educating for trust. Arch Sci, $11,373-390$.

Duranti, L., \& Jansen, A. (2013). Records in the cloud: Authenticity and jurisdiction. Digital Heritage International Congress (DigitalHeritage), 161-164.

Evans, J., Reed, B., \& Linger, H. (2014). Winds of change: A recordkeeping informatics approach to information management needs in data-driven research environments. Records Management Journal, 24(3), 205-223.

Evans, M. R. (2015). Modern special collections: Embracing the future while taking care of the past. New Review of Academic Librarianship, 21(2), 116-128.

Garcia, C., Davila, A., \& Pessoa, M. (2014). Test process models: Systematic literature review. In A. Mitasiunas, T. Rout, R. O'Connor, \& A. Dorling, Software Process Improvement and Capability Determination. SPICE 2014. Communications in Computer and Information Science. New York: Springer. 
Goldman, B., \& Pyatt, T. D. (2013). Security without obscurity: Managing personally identifiable information in born-digital archives. Library \& Archival Security, 26(1-2), 37-55.

Grant, R. (2017). Recordkeeping and research data management: a review of perspectives. Records Management Journal, 27(2), 159174.

Kemoni, H. N. (2009). Management of electronic records: Review of empirical studies from the Eastern, Southern Africa Regional Branch of the International Council on Archives (ESARBICA) region. Records Management Journal, 19(3), 190203.

Khabsa, M., \& Giles, C. L. (2014). The number of scholarly documents on the public web. PLoS One, 9(5), 39-49.

Kominfo. (2019). Kominfo Beberkan Sederet Kasus Hoax di WhatsApp. Retrieved 20 October 2019 from Kominfo: https://kominfo.go.id/content/detail/16023 /kominfo-beberkan-sederet-kasus-hoax-diwhatsapp/0/sorotan media

Latham, K. F. (2010). Medium rare: Exploring archives and their conversion from original to digital (Part One). LIBRES Library and Information Science Research Electronic Journal, 20(2), 1-14.

Luciana, D. (2010). The long-term preservation of the digital heritage: A case study of universities institutional repositories. Journal of Library and Information Sciences, 1(1), 157-168.

Merriam-webster. (2019). merriam-webster. Diakses 20 Agustus, 2019 , dari https://www.merriam-webster.com/

Mosweu, O., \& Ngoepe, M. (2019). Skills and competencies for authenticating digital records to support audit process in Botswana public sector. African Journal of Library, Archives \& Information Science, 29(1), 17-28.

OAIS. (2012). Reference Model for an Open Archival Information System (OAIS). Washington, DC: Magenta Book, Consultative Committee for Space Data Systems.
Okoli, C., \& Schabram, K. (2010). A guide to conducting a systematic literature review of information systems research. Sprouts: Working Papers on Information Systems, 10(26), 1-51.

Ormond-Parker, L., \& Sloggett, R. (2012). Local archives and community collecting in the digital age. Archival Science, 12, 191-212.

Pertiwi, W. K. (2019). Cara Kirim Foto di WhatsApp Tanpa Menurunkan Kualitas. Retrieved 24 July 2019 from $\mathrm{t}$ e $\mathrm{k} \mathrm{n} \mathrm{o.} \mathrm{k}$ o $\mathrm{m} \mathrm{p}$ a s . c o m : https://tekno.kompas.com/read/2019/07/2 4/10150007/cara-kirim-foto-di-whatsapptanpa-menurunkan-kualitas

Petticrew, M., \& Roberts., H. (2006). Systematic Reviews in the Social Sciences: A Practical Guide. Blackwell Publishing.

Pinnick, J. (2017). Exploring digital preservation requirements. Records Management Journal, 27(2), 175-191.

Price, D. M., \& Smith, J. J. (2011). The trust continuum in the information age: A Canadian perspective. Arch Sci, 11, 253-276.

Rogers, C. (2016). A literature review of authenticity of records in digital systems from 'machine-readable' to records in the cloud. Acervo, Rio de Janeiro, 29(2), 16-44.

Sabharwal, A. (2017). Digital humanities and the emerging framework for digital curation. College \& Undergraduate Libraries, 24(2-4), 238-256.

Shaikh, M., Salleh, N., \& Marziana, L. (2015). Social networks event mining: A systematic literature review. In A. Abraham, A. Muda, \& Y. Choo, Pattern Analysis, Intelligent Security and the Internet of Things. Advances in Intelligent Systems and Computing. New York: Springer.

Tammaro, A. M. (2016). Heritage Curation in the Digital Age: Professional Challenges and Opportunities. International Information \& Library Review, 48(2), 122128. 
Uman, L. S. (2011). Systematic Reviews and Meta-Analyses. Journal of The Canadian Academy of Child and Adolescent Psychiatry, 20(1), 57-59.

Van Bussel, G.-J. (2012). Reconstructing the Past for Organizational Accountability. Electronic Journal Information Systems Evaluation, 15(1), 127-137.

Wei, G., Fang, Y., Pan, W., \& Dekun, L. (2016). Archives as a trusted third party in maintaining and preserving digital records in the cloud environment. Records Management Journal, 26(2), 170-184.
Zhu, Y. (2017). Authenticity and Heritage Conservation in China: Translation, Interpretation, Practices. In G. N. In: Weiler K., Authenticity in Architectural Heritage Conservation. Transcultural Research Heidelberg Studies on Asia and Europe in a Global Context (pp. 187-200). Switzerland: Springer. 


\section{DAFTAR GAMBAR}

\section{Tahapan Tinjauan Literatur Sistematis (SLR)}

\begin{tabular}{|l|l|l|}
\hline \multicolumn{1}{|c|}{ Perencanaan } & \multicolumn{1}{c|}{ Pelaksanaan } & \multicolumn{1}{c|}{ Pelaporan } \\
\hline $\begin{array}{l}\text { 1. Menentukankonteks } \\
\text { pencarian }\end{array}$ & $\begin{array}{l}\text { 1. Membentuk strategi } \\
\text { pencarian, identifikasistilah }\end{array}$ & $\begin{array}{l}\text { 1. Menggabungkan data dalam } \\
\text { format excel }\end{array}$ \\
$\begin{array}{l}\text { 2. Mendefinisikan review } \\
\text { protocol } \text { protokol tinjaun }\end{array}$ & $\begin{array}{l}\text { pencarian, melakukan proses } \\
\text { pencarian }\end{array}$ & $\begin{array}{l}\text { Mendokumentasikan hasil } \\
\text { penelitian }\end{array}$ \\
$\begin{array}{l}\text { 3. Menyusun pertanyaan } \\
\text { penelitian }\end{array}$ & $\begin{array}{l}\text { 2. Memilih kajian primer dan } \\
\text { sekunder }\end{array}$ & \\
\hline
\end{tabular}

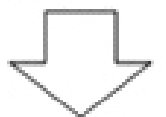

Review ProtocolProtokol Tinjauan

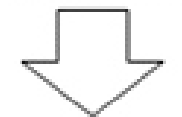

Data Items/Item Data

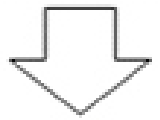

Hasil dan Diskusi

Gambar 1. Tahapan Tinjauan Literatur Sistematis (SLSR)

Sumber: Adrian, Abdullah, Atan, \& Jusoh (2016)

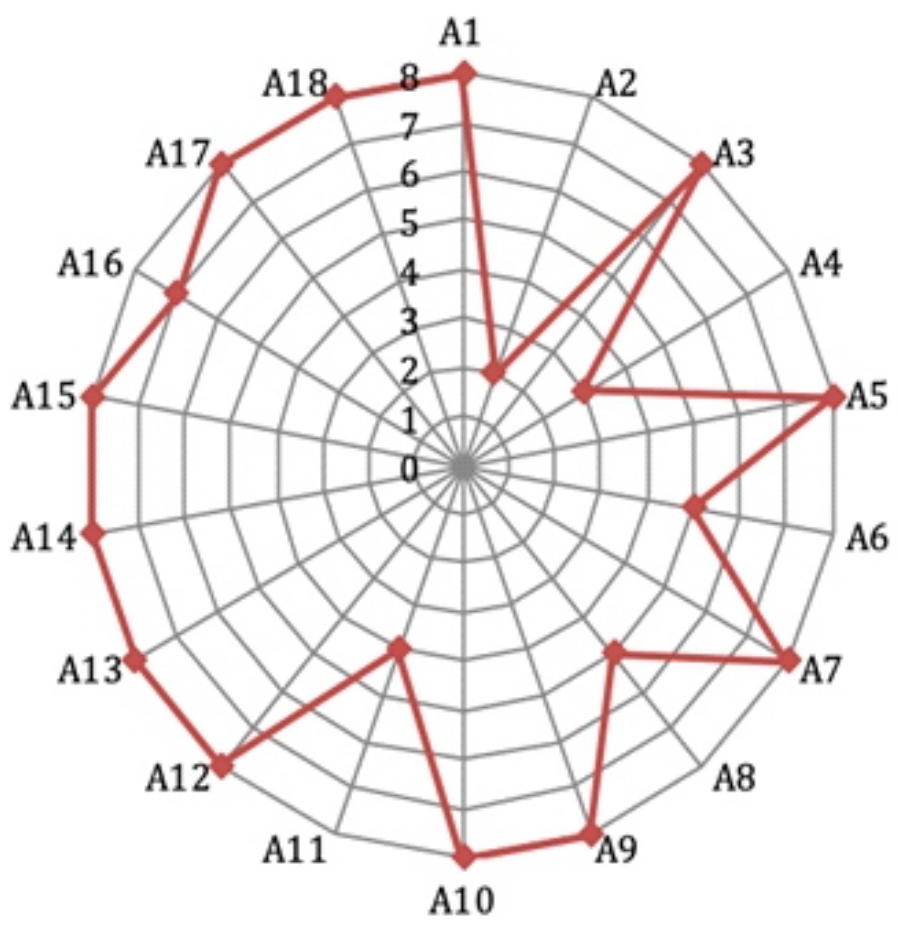

Gambar 2. Hasil penilaian penyaringan artikel terpilih Sumber: hasil penelitian, 2019 


\section{DAFTAR TABEL}

Tabel 1. Cakupan untuk menyusun pertanyaan penelitian

\begin{tabular}{|c|c|c|}
\hline No. & Kriteria & Cakupan \\
\hline 1. & Populasi & Arsip Elektronik / Rekod Elektronik / Dokumen Elektronik \\
\hline 2. & Intervensi & $\begin{array}{l}\text { Batasan pada penelitian tentang mempertahankan keaslian arsip elektronik di era } \\
\text { digital }\end{array}$ \\
\hline 3. & Komparasi & Tidak tersedia \\
\hline 4. & Hasil & Upaya-upaya untuk mempertahankan keaslian arsip elektronik di era digital \\
\hline 5. & Konteks & $\begin{array}{l}\text { Tinjauan tentang semua penelitian tentang upaya mempertahankan keaslian arsip } \\
\text { elektronik di era digital }\end{array}$ \\
\hline
\end{tabular}

Sumber: hasil penelitian, 2019

Tabel 2. Penentuan kriteria inklusi dan eksklusi

\begin{tabular}{|c|c|c|}
\hline & Inklusi / Penyertaan & Eksklusi / Pengecualian \\
\hline 1. & $\begin{array}{l}\text { Semua literatur yang diterbitkan dalam } \\
\text { bahasa Inggris }\end{array}$ & $\begin{array}{l}\text { Semua literatur yang diterbitkan tidak } \\
\text { menggunakan bahasa Inggris }\end{array}$ \\
\hline 2. & $\begin{array}{l}\text { Semua literatur yang diterbitkan dari periode } \\
1 \text { Januari } 2010 \text { sampai dengan } 30 \text { April } 2019\end{array}$ & $\begin{array}{l}\text { Semua literatur yang diterbitkan sebelum } \\
\text { tahun } 2010 \text { dan/atau di luar cakupan } \\
\text { periode inklusi }\end{array}$ \\
\hline 3. & $\begin{array}{l}\text { Semua literatur yang termasuk ke dalam } \\
\text { kategori artikel jurnal }\end{array}$ & $\begin{array}{l}\text { Semua literatur yang tidak termasuk ke } \\
\text { dalam kategori artikel jurnal }\end{array}$ \\
\hline 4. & $\begin{array}{l}\text { Semua literatur yang dapat diakses secara } \\
\text { utuh (full) }\end{array}$ & $\begin{array}{l}\text { 4. Semua literatur yang tidak dapat diakses } \\
\text { secara utuh (full) }\end{array}$ \\
\hline 5. & $\begin{array}{l}\text { Semua literatur yang termasuk ke dalam } \\
\text { kelompok ilmu perpustakaan dan informasi }\end{array}$ & $\begin{array}{l}\text { 5. Semua literatur di luar kelompok ilmu } \\
\text { perpustakaan dan informasi }\end{array}$ \\
\hline
\end{tabular}

Sumber: hasil penelitian, 2019

Tabel 3. Kriteria penilaian kualitas penelitian

\begin{tabular}{clc}
\hline ID Kualitas & \multicolumn{1}{c}{ Pertanyaan Penilaian Kualitas } & Jawaban \\
\hline P1 & $\begin{array}{l}\text { Apakah terdapat penjelasan yang cukup terhadap tujuan dan } \\
\text { sasaran dari penelitian? }\end{array}$ & Ya / Sebagian / Tidak \\
P2 & $\begin{array}{l}\text { Apakah penelitian itu membahas tentang keaslian arsip } \\
\text { (termasuk rekod dan dokumen) }\end{array}$ & Ya/ Tidak \\
P3 & $\begin{array}{l}\text { Apakah penelitian tersebut membahas tentang arsip } \\
\text { elektronik (termasuk rekod dan dokumen elektronik) } \\
\text { Apakah penelitian itu menjelaskan cara-cara untuk } \\
\text { P4 }\end{array}$ & Ya / Sebagian / Tidak \\
\hline
\end{tabular}

Sumber: hasil penelitian, 2019 


\section{DAFTAR TABEL}

Tabel 4. Rincian bibliografis dan hasil penilaian artikel

\begin{tabular}{|c|c|c|c|c|c|}
\hline Kode & Penulis & Judul & Nama Jurnal & $\begin{array}{l}\text { Tahun } \\
\text { Terbit }\end{array}$ & Nilai \\
\hline A1 & Sharon Adam & Preserving authenticity in the digital age & Library Hi Tech & 2010 & 8 \\
\hline $\mathrm{A} 2$ & $\begin{array}{l}\text { Lyndon Ormond- } \\
\text { Parker, Robyn } \\
\text { Sloggett }\end{array}$ & $\begin{array}{l}\text { Local archives and community collecting in the } \\
\text { digital age }\end{array}$ & Archival Science & 2012 & 2 \\
\hline A3 & $\begin{array}{l}\text { Mosweu, Olefhile; } \\
\text { Ngoepe, Mpho. }\end{array}$ & $\begin{array}{l}\text { Skills and Competencies for Authenticating } \\
\text { Digital Records to Support Audit Process in } \\
\text { Botswana Public Sector }\end{array}$ & $\begin{array}{l}\text { African Journal of Library, } \\
\text { Archives \& Information Science }\end{array}$ & 2019 & 8 \\
\hline A4 & $\begin{array}{l}\text { Anna Maria } \\
\text { Tammaro }\end{array}$ & $\begin{array}{l}\text { Heritage Curation in the Digital Age: } \\
\text { Professional Challenges and Opportunities }\end{array}$ & $\begin{array}{l}\text { International Information \& } \\
\text { Library Review }\end{array}$ & 2016 & 3 \\
\hline A5 & $\begin{array}{l}\text { Evans, Joanne; } \\
\text { Reed, Barbara; } \\
\text { Linger, Henry; } \\
\text { More... }\end{array}$ & $\begin{array}{l}\text { Winds of change: A recordkeeping informatics } \\
\text { approach to information management needs in } \\
\text { data-driven research... }\end{array}$ & Records Management Journal & 2014 & 8 \\
\hline A6 & Kiersten F Latham & $\begin{array}{l}\text { Medium Rare: Exploring Archives and their } \\
\text { Conversion from Original to Digital: Part One: } \\
\text { Lessons from the History of Print... }\end{array}$ & $\begin{array}{l}\text { LIBRES: Library and } \\
\text { Information Science Research } \\
\text { Electronic Journal }\end{array}$ & 2010 & 5 \\
\hline A7 & $\begin{array}{l}\text { Luciana } \\
\text { DurantiCorinne } \\
\text { Rogers }\end{array}$ & Educating for trust & Archival Science & 2011 & 8 \\
\hline A8 & Luciana Duranti & $\begin{array}{l}\text { The long-term preservation of the digital } \\
\text { heritage: the case of universities institutional } \\
\text { repositories }\end{array}$ & $\begin{array}{l}\text { Journal of Library And } \\
\text { Information Sciences }\end{array}$ & 2010 & 5 \\
\hline A9 & Arjun Sabharwal & $\begin{array}{l}\text { Digital humanities and the emerging framework } \\
\text { for digital curation }\end{array}$ & $\begin{array}{l}\text { College \& Undergraduate } \\
\text { Libraries }\end{array}$ & 2017 & 8 \\
\hline A10 & $\begin{array}{l}\text { Goldman, Ben; } \\
\text { Pyatt, Timothy D }\end{array}$ & $\begin{array}{l}\text { Security Without Obscurity: Managing } \\
\text { Personally Identifiable Information in Born- } \\
\text { Digital Archives }\end{array}$ & Library \& Archival Security & 2013 & 8 \\
\hline A11 & Rebecca Grant & $\begin{array}{l}\text { Recordkeeping and research data management: a } \\
\text { review of perspectives }\end{array}$ & Records Management Journal & 2017 & 4 \\
\hline A12 & Peter Burnhill & $\begin{array}{l}\text { Tales from The Keepers Registry: Serial Issues } \\
\text { About Archiving \& the Web }\end{array}$ & Serials Review & 2013 & 8 \\
\hline A13 & Evans, Meredith R & $\begin{array}{l}\text { Modern Special Collections: Embracing the } \\
\text { Future While Taking Care of the Past }\end{array}$ & $\begin{array}{l}\text { New Review of Academic } \\
\text { Librarianship }\end{array}$ & 2015 & 8 \\
\hline A14 & $\begin{array}{l}\text { Price, Dara M; } \\
\text { Smith, Johanna J }\end{array}$ & $\begin{array}{l}\text { The trust continuum in the information age: a } \\
\text { Canadian perspective }\end{array}$ & Archival Science & 2011 & 8 \\
\hline A15 & Frederick B. Cohen & $\begin{array}{l}\text { Digital diplomatics and forensics: going forward } \\
\text { on a global basis }\end{array}$ & $\begin{array}{l}\text { Records Management } \\
\text { Journal }\end{array}$ & 2015 & 8 \\
\hline A16 & Geert-Jan van Bussel & $\begin{array}{l}\text { Reconstructing the Past for Organizational } \\
\text { Accountability }\end{array}$ & $\begin{array}{l}\text { Electronic Journal of } \\
\text { Information Systems } \\
\text { Evaluation }\end{array}$ & 2012 & 7 \\
\hline A17 & Jaana Pinnick & $\begin{array}{l}\text { Exploring digital preservation requirements: A } \\
\text { case study from the National Geoscience Data } \\
\text { Centre (NGDC) }\end{array}$ & $\begin{array}{l}\text { Records Management } \\
\text { Journal }\end{array}$ & 2017 & 8 \\
\hline A18 & $\begin{array}{l}\text { Wei Guo, Yun Fang, } \\
\text { Weimei Pan, Dekun } \\
\text { Li, }\end{array}$ & $\begin{array}{l}\text { Archives as a trusted third party in maintaining } \\
\text { and preserving digital records in the cloud } \\
\text { environment }\end{array}$ & $\begin{array}{l}\text { Records Management } \\
\text { Journal }\end{array}$ & 2016 & 8 \\
\hline
\end{tabular}

Sumber: hasil penelitian, 2019 